\title{
AVALIAÇÃO DA EDUCAÇÃO BÁSICA E AÇÃO NORMATIVA FEDERAL
}

\author{
DIRCE NEI TEIXEIRA DE FREITAS \\ Universidade Federal de Mato Grosso do Sul \\ dircenei@terra.com.br
}

\begin{abstract}
RESUMO
Examina-se a ação normativa federal concernente à avaliação nacional da educação básica, no Brasil, do período de 1995 a 2002, com o objetivo de evidenciar sua extensão e natureza como faceta da regulação educacional, durante os oito anos do Governo Fernando Henrique Cardoso. Verifica-se, nesse período, extraordinária ampliação dos meios e do instrumental de regulação federal da "qualidade" do ensino, conjugando as vias de medida e avaliação. Constata-se intensa intervenção do Poder Executivo, que sinaliza alterações constitucionais e a edição de leis, amplia a regulamentação da área e amplifica a regulação normativa federal. Esse quadro normativo permite entender como se exerce o poder e se concretiza o Estado-Regulador no país.

EDUCAÇÃOBÁSICA-LEGISLAÇÃODOENSINO-AVALAAÇÃODAEDUCAÇÃO
\end{abstract}

\begin{abstract}
BASICEDUCATIONEVALUATIONANDFEDERAL REGULATORY ACTIONS. Thefederalregulatory actions are examined in regard with the national evaluation of basic education in Brazil, from 1995 to 2002, with the purpose of emphasizing their extension and nature as an aspect of educational regulation during the eight years of the Fernando Henrique Cardoso administration. In that period, we saw an extraordinary widening of the means and tools in the federal regulation of education "quality", combining measurement and evaluation methods. An intense intervention by the Executive branch is seen, signaling constitutiona/modifications and the editing of laws, widening the regulations of the area and extending the federa/ normative regulation. This normative scenario allows one to understand how power is used and how the Regulating-State manifests itself in the country. BASICEDUCATION-EDUCATIONAL LEGISLATION-EDUCATIONEVALUATION
\end{abstract}

texto apresenta resultados de estudos realizados no âmbito de pesquisa em desenvolvimento junto à pós-graduação da Faculdade de Educação da Universidade de São Paulo, sob orientação da professora Sandra Maria Zákia Lian Sousa. 
No decorrer dos anos de 1990, acentuadamente no período posterior a 1994, a sociedade brasileira viu ganhar centralidade o tema da qualidade do ensino como objeto de regulação federal, cuja viabilidade exigira o aporte de um sistema de informações educacionais conjugado a um sistema nacional de avaliação, considerados ambos elementos estratégicos da boa-governançal educacional no país.

Este trabalho tem o objetivo de mostrar como a avaliação da educação básica brasileira se configurou na ação normativa federal do período de 1995 a 2002, que corresponde aos dois mandatos de governo de Fernando Henrique Cardoso - FHC.

A configuração inicial do Sistema Nacional de Avaliação da Educação Básica - Saeb - teve lugar no fim da década de 1980, vindo a consolidar-se na segunda metade dos anos de 1990, quando foi também reestruturado e "modernizado" o sistema de estatísticas e indicadores educacionais. Nesse período, foram ampliados os meios operacionais de centralização da avaliação educacional com a inclusão de exames nacionais: o Exame Nacional do Ensino Médio - Enem - e o Exame Nacional de Certificação de Competências de Jovens e Adultos - Encceja.

A instância federal ampliou sua ação avaliativa no interior de programas como o do livro didático - PNLD - e o do Fundo de Fortalecimento da Escola - Fundescola -, neste especialmente com o projeto Plano de Desenvolvimento da Escola - PDE. Com o aval de governos subnacionais, o PDE introduziu uma "tecnologia" de planejamento estratégico em escolas públicas das regiões Nordeste, Norte e Centro-Oeste, que ensejou a condução externa da avaliação institucional e a realização, conforme assinalou Franco (200 I ), de avaliações longitudinais.

Além disso, foram estabelecidas normas legais que propiciaram a criação, pelos sistemas de ensino e escolas, de mecanismos flexibilizadores da avaliação da aprendizagem, especialmente importantes na regulação do fluxo escolar, a exemplo da classificação/reclassificação, progressão continuada e progressão parcial. Esses mecanismos apareceram associados à flexibilização da

\footnotetext{
Usa-se o termo "governança" no sentido de exercício dinâmico do ato de governar que implica capacidade de coordenação, de liderança, de implementação e de produção de credibilidade (Costa, 1997).
} 
organização da educação básica (ciclos, alternância de períodos de estudos, grupos não seriados e outros), à possibilidade de aceleração de estudos para alunos com atraso escolar e à obrigatoriedade de estudos de recuperação, preferentemente paralelos ao período letivo.

Sobretudo, destacou-se na iniciativa federal a avaliação padronizada em larga escala, que, segundo Locatelli (2002, p.5), então diretora de avaliação da educação básica do Instituto Nacional de Estudos e Pesquisas Educacionais Inep -, teria passado a assumir "papel central na formulação e implementação de políticas públicas". No caso da avaliação da educação básica, com o objetivo de "monitorar a qualidade" 2 e com o desafio de fazer com que diferentes atores incorporassem a avaliação externa em seu cotidiano vendo-a como apoio para melhorar a qualidade do ensino.

Ferrer ( 1996 ) chamou a atenção para o crescente interesse pela avaliação educacional e a extensão da avaliação de sistemas de ensino, no contexto internacional, a partir da influência do impulso dado à avaliação educacional nos Estados Unidos, com a aprovação do Primary and Secondary Education Act, em 1965, e a publicação do Informe Coleman em 1968. No âmbito internacional, foi importante a criação da Internacional Association for the Evaluation of Educacional Achievement - IEA -, propondo-se a promover e realizar estudos internacionais de avaliação educacional, bem como a experiência de construção, nos anos de 1970, de indicadores internacionais de qualidade da educação pela Organização para a Cooperação e Desenvolvimento Econômico OCDE.

crescente interesse pela avaliação de sistemas educacionais nos anos de 1980 levou à criação de mecanismos institucionais, centros, organismos e planos sistemáticos de avaliação, e à elaboração de indicadores nacionais de educação, entre outros, em um número crescente de países nas mais diversas regiões do mundo. Esse aumento de interesse teria como motivação, segundo Ferrer (1996), a pressão das mudanças contextuais sobre os sistemas de ensino: mudanças nos modos de administração e controle desses sistemas; demanda social de informação e prestação de contas; novo modelo de gestão educacional.

2 O monitoramento relaciona-se com a gestão administrativa e consiste no exame contínuo ou periódico da operacionalização do previsto, visando a controlar o cumprimento do que foi estabelecido (Cepal, 1995). 
No Brasil, conforme Sousa (1997), a avaliação educacional, como questão afeta ao poder público, desconsiderou contribuições da pesquisa, de que são exemplos as iniciativas de testagem introduzidas nos anos de 1980. Enquanto os estudos apontavam para as implicações educacionais e sociais da avaliação, o poder público recorria à testagem do rendimento do aluno, sendo este tomado como expressão do desempenho de escolas e sistemas.

Este estudo se detém na configuração da ação normativa federal concernente à avaliação nacional da educação básica no Brasil, no período de 1995 a 2002, com o objetivo de evidenciar sua extensão e natureza como faceta da regulação educacional nos oito anos do Governo FHC. Considera-se, com Sousa (1999), que a avaliação é procedimento político e, como tal, expressão de um dado projeto educacional e social.

Trabalha-se com os principais instrumentos da ação normativa jurídicolegal e administrativa, observando, sempre que possível, a seqüência cronológica de edição das normas. Recorre-se, também, à literatura referente à avaliação de sistemas de ensino e à análise de políticas educacionais.

Importa lembrar que a avaliação consiste um domínio em configuração no campo da pesquisa educacional (Freitas, 2002), sendo que o tipo de avaliação aqui privilegiado se encontra em estágio incipiente no país, verificando-se a predominância do discurso oficial e a forte referência a experiências internacionais nas produções de boa parte dos anos de 1990 (Barretto et al., 200 I). O estudo sofre, portanto, as restrições decorrentes desse quadro.

\section{REGULAÇÃO NORMATIVA ANTES DE 1995}

O que existia em termos de "avaliação nacional" da educação básica quando, em 1995, iniciaram-se os oito anos de Governo FHC? A indagação remete à consideração do tema numa perspectiva de movimento (mudançapermanência) e de processo contextualizado.

\section{marco jurídico}

É preciso considerar, primeiramente, o que já estava estabelecido a respeito da avaliação da educação básica na norma jurídica. 
No texto constitucional de 1988 (Brasil, 1988), encontram-se disposições que remetem ao problema da avaliação da/na educação básica. No art. 206, a "garantia de padrão de qualidade" figura como um dos princípios basilares do ensino, suscitando questionamentos que dizem respeito também à avaliação educacional. Entre outros: o que é qualidade? Como aferir a qualidade do ensino? Qual o padrão de qualidade? Como estabelecê-lo com propriedade? Como garantir um determinado padrão de qualidade do ensino e que contribuição pode dar a avaliação?

No art. 209, a avaliação da qualidade pelo poder público aparece como condição do ensino livre à iniciativa privada. Em um Estado cuja ordem constitucional tem por fundamentos declarados princípios liberais, requerer da iniciativa privada sujeição à avaliação do Poder Público supõe antes que esta ocorra no ensino público.

art. 2 | 4, tratando do plano nacional de educação, indica como um dos resultados pretendidos a "melhoria da qualidade do ensino". Este dispositivo suscita questões que supõem definições com vistas na sua aplicação, como a de saber em que consiste tal melhoria e tal qualidade, qualidade por que ótica, para quem e para que, o que, quanto, como, onde e quando melhorar e como aferir tal melhoria. São questões que colocam a avaliação em evidência.

A avaliação educacional é, pois, uma questão que emerge do texto constitucional de 1988 e, portanto, se impõe como tarefa pública que, compreendida no contexto da norma jurídica maior, supõe a atuação do Estado e do governo segundo a concepção de federalismo e da natureza da relação Estado-sociedade nela inscrita. Definições decorrentes deverão enfrentar, entre outras, questões como: a quem cabe torná-la efetiva, em que campo, quando, onde, quanto e como.

\section{Regulamentação inicial}

Dar conseqüência prática a tais dispositivos constitucionais não prescindia de uma nova regulamentação, devido à ineficácia da Lei n. 4.024, de 20/ 12/1961, diante das alterações jurídicas introduzidas pela Constituição Federal de 1988. Antes disso, porém, a "avaliação nacional" da educação básica existiu, de 1987 a 1990, na forma de programa do Ministério da Educação MEC - denominado Sistema de Avaliação do Ensino Público de $1{ }^{\circ}$ Grau - Saep. 
A partir de 1992, com alterações, esse programa deu origem ao Sistema de Avaliação da Educação Básica - Saeb. Essa atuação do MEC prescindiu de regulamentação legal até a edição da Medida Provisória n. 66। de 18.10.1994 (Brasil, 200 ld).

Os embates em torno de uma nova Lei de Diretrizes e Bases da Educação Nacional - LDB - ${ }^{3}$, formalmente iniciado em outubro de 1988, estenderam-se até dezembro de 1996. Devido a isso, o governo buscou alterar a Lei n. 4.024/6I (Brasil, 200I) mediante a edição da mencionada Medida Provisória. Ela continha, entre outros, dispositivos que propiciariam a regulamentação da atuação do MEC na "avaliação da qualidade do ensino".

Atribuições do Conselho Federal de Educação passaram a figurar como competências do MEC. Este Conselho (agora Conselho Nacional de Educação), foi reduzido a um órgão, subordinado ao MEC, mantendo, porém, competências que guardavam relação com a avaliação educacional.

A eficácia dessa Medida Provisória foi assegurada com sua reedição sob o n. 7II, em 17//I/1994, e n. 765, em 16/12/1994 (Brasil, 200 I e). Somente nesse momento o MEC tomou medidas que visaram a formalizar o Saeb fundando-o em base legal. Tomando como fundamento legal essa Medida Provisória reeditada, o Ministro da Educação instituiu uma comissão especial encarregada de providências com vistas à criação formal desse programa. Tal comissão propôs uma estrutura para o Saeb que propiciava sua execução descentralizada, com um núcleo técnico e diretivo no MEC e nas Secretarias Estaduais de Educação, encarregado de supervisionar o desenvolvimento do sistema e assegurar a relação avaliação-formulação de políticas (Bonamino, Martínez, 2002).

A Portaria n. 1.795, de 27.12.1994, formalizou a criação do Saeb (Brasil, 1994) com uma estrutura consoante ao teor da proposta daquela comissão, refletindo, conforme ressaltaram Bonamino e Martínez (2002, p.96), o "arranjo institucional característico dos dois primeiros ciclos de avaliação, em 1990 e 1993". Prevalecia, assim, uma perspectiva oposta à defendida por técnicos

3 ○ tratamento dado à avaliação da educação básica no processo de elaboração da Lei n. 9.394/96, ainda que seja importante na configuração do quadro normativo federal, não é objeto deste trabalho. 
do Banco Mundial, com base em estudos realizados em alguns países da América Latina, os quais propunham uma organização em que caberia ao MEC apenas definir e controlar objetivos gerais da avaliação, deixando a execução das atividades do programa para organizações não-lucrativas.

Ao término de 1994, o Saeb apresentava uma institucionalização incipiente e um fundamento legal provisório. No entanto, vinha se configurando na prática, a partir de iniciativas da administração federal.

Iniciativas da parte de administrações estaduais ocorreram a partir de 1992. A experiência de avaliação de Minas Gerais, entre 1992 e 1993, na gestão de Walfrido Mares-Guia na Secretaria de Educação do Estado, foi realizada no contexto de uma reforma educacional assessorada por técnicos da Fundação Carlos Chagas, do Banco Mundial e da Organização Internacional do Trabalho - OIT -, e constituiu, segundo Cunha (1995), uma das fontes de inspiração do Saeb. Bonamino e Martínez $(2002$, p.65, 94) alertam, porém, para as especificidades das experiências e assinala de que nem a importância de experiências locais nem o poder exercido pelos organismos internacionais devem obscurecer o fato de que foram "as altas hierarquias do MEC [que, nos anos de 1990] revestiram a avaliação educacional de uma importância inédita", sendo evidente "a paternidade dos agentes internos" na configuração do sistema nacional de avaliação da educação básica.

\section{REGULAÇÃO NORMATIVA NO PERÍODO DE 1995 A 2002}

No período 1995 a 2002, verificou-se a ampliação dos meios de centralização da avaliação/medida da educação básica, conforme se mostra a seguir.

A Medida Provisória n. 66 I/94 - reeditada, sem alterações, sob o n. 71 I/ 94 e depois sob o n. 765/94 - propiciou a criação formal do Saeb, conforme assinalado. Este mesmo texto foi mantido nas reedições de n. 830, n. 89। e n. 938 de janeiro, fevereiro e março de 1995, respectivamente. Mas, na reedição n. 967, de 13.4.1995, já estavam inseridas modificações que permaneceriam posteriormente e que, com outras alterações nas reedições n. 992, de 12.5. 1995 e n. I.094, de 28. I I.1995, culminariam no texto final da lei n. 9.13। de 24.1 I.1995 (Brasil, 200 Ia).

É amplamente conhecido que esta lei antecipou a solução de questões em debate no processo de formulação da nova LDB, dentre elas o papel da 
União e de suas estruturas político-administrativa e normativa: MEC e ConseIho Nacional de Educação.

A lei centraliza a avaliação no MEC e retira do Conselho Nacional de Educação as incumbências relativas a ela. Esse movimento fica em grande parte assegurado já na Medida Provisória reeditada sob o n. 967, de 13.4.1994 (Brasil, 200 If).

Ainda em 1995, o Ministério da Educação iniciou um processo avaliativo com vistas à "melhoria da qualidade do livro didático" do ensino fundamental público de todo o país. Esse processo envolveu, além de dirigentes e técnicos do MEC e da então Fundação de Assistência ao Estudante - FAE -, especialistas de diversas áreas, editores, autores, e entidades como a União Nacional dos Dirigentes Municipais de Educação - Undime -, o Conselho Nacional de Secretários de Educação - Consed -, a Câmara Brasileira do Livro - CBL -, a Associação Brasileira dos Autores de Livros Educativos - Abrale -, a Associação Brasileira dos Editores de Livros - Abrelivros - e o Sindicato Nacional dos Editores de Livros - SNEL.

Os livros passaram a ser avaliados segundo critérios acordados, classificados e caracterizados em um Guia de Livros Didáticos. A avaliação pedagógica do livro didático só foi regulamentada pela Portaria Ministerial n. 82, de 20. I.2000 (Brasil, 2000a). À Secretaria de Educação Fundamental (SEF) coube realizar, a cada três anos, a Avaliação Pedagógica do Livro Didático com o objetivo de indicar os recomendados para aquisição e distribuição pelo Plano Nacional do Livro Didático. Para tanto, deveria ser assessorada por uma comissão técnica que, segundo o art. $2^{\circ}$ dessa Portaria, seria composta por "professores e especialistas de reconhecido saber nas áreas de Língua Portuguesa, inclusive Alfabetização, Matemática, Ciências, História e Geografia, indicados pela própria SEF e designados pelo Ministro de Estado da Educação".

Em 1996, a redefinição de papéis e atribuições no âmbito da administração federal, iniciada com as medidas provisórias mencionadas, ocorreu mais amplamente com as alterações do texto constitucional de 1988, a edição da LDB/96 e regulamentações. No interior destas mudanças, explicitam-se função e bases da avaliação na gestão da educação básica no país.

A Emenda Constitucional n. 14, de 12.9. 1996 introduziu mudanças substanciais no tocante à administração da educação básica (Brasil, 2001 m). Seguiu, à promulgação dessa Emenda Constitucional, a sanção da Lei n. 9.394, de 20. I 2. 1996 (LDB/96), explicitando-se a "solução" para os embates ocorridos 
no longo processo de elaboração dessa lei (1988-1996). A LDB introduziu dispositivos sobre avaliação medida e controle na regulação da qualidade do ensino em escala nacional, conforme segue.

Art. $9^{\circ}$. A União incumbir-se-á de:

$\checkmark$ - coletar, analisar e disseminar informações sobre a educação;

$\mathrm{VI}$ - assegurar processo nacional de avaliação do rendimento escolar no ensino fundamental, médio e superior, em colaboração com os sistemas de ensino, objetivando a definição de prioridades e a melhoria da qualidade do ensino;

$\S 2^{\circ}$ Para o cumprimento do disposto nos incisos $\vee$ a IX, a União terá acesso a todos os dados e informações necessários de todos os estabelecimentos e órgãos educacionais. (Brasil, 1999)

Obtenção, análise e divulgação de informações sobre a educação e a avaliação de rendimento escolar - como incumbências da União "em colaboração com os sistemas de ensino" - foram estabelecidas em lei, em vista dos objetivos de definição de prioridades e de melhoria da qualidade do ensino. Desse modo, foi deixado a cargo da União, ou do MEC, nos termos da Lei n. 9. I31/95, o não-definido e o não-estabelecido que pudesse vir a ser fundamentado nos dispositivos da LDB/96.

Tal sistema de avaliação pode ser visto como a forma pela qual a União colabora com estados e municípios e estes com a União.

Além disso, a LDB/96 estabeleceu, no seu art. 87 ( $\S 3^{\circ}$, inciso IV), como dever dos municípios e, supletivamente, dos estados e da União, a integração de todos os estabelecimentos de ensino fundamental ao sistema nacional de avaliação do rendimento escolar até o final da Década da Educação (19972007).

Dentro das possibilidades abertas à ação reguladora da administração federal com a Emenda Constitucional de n. I4/96 e com a LDB/96, o Saeb teria sido orientado para o monitoramento. Para Castro (1998), seu papel central seria o de monitorar a "descentralização" de políticas num contexto de redefinição de competências dos três níveis de governo propiciados pelos instrumentos legais. Mas a avaliação, que, conforme a Comissão Econômica para a América Latina e Caribe - Cepal (1995), privilegia a relação entre alcance de objetivos e custo, parece ter sido sobreposta ao monitoramento.

Na perspectiva da organização de um sistema de informações e indica- 
dores educacionais, além do Saeb o governo federal cuidou da realização de censos educacionais, com destaque para o censo escolar fundamentado no art. 208, § $3^{\circ}$ da Constituição Federal e na Lei n. 9.394/96, art. 5ª $\S 1^{\circ}$, inciso I e art. $9^{\circ}$, inciso $\mathrm{V}$.

A Lei n. 9.424, de 24//2/l 996 (Brasil, 200 I b), fixou os dados oficiais do censo escolar sobre a matrícula no ensino fundamental como base para a distribuição dos recursos do Fundo de Expansão e Desenvolvimento do Ensino Fundamental e Valorização do Magistério - Fundef-, determinou que as estatísticas necessárias para o cálculo do valor anual mínimo por aluno (inclusive as estimativas de matrículas) tomassem como base este censo e atribuiu ao MEC a responsabilidade de realizá-lo anualmente, publicando os resultados.

Com o Decreto n. 2.264, de 1997, que regulamenta a aplicação dessa lei, o Executivo federal estabeleceu de forma mais explícita, o papel do censo escolar na operacionalização da nova sistemática de financiamento do ensino fundamental (Brasil, 200 Ik). Mediante a Portaria Ministerial n. 177, de 1998, o Ministro da Educação delegou ao Inep a responsabilidade de coordenar o censo escolar e definiu as ações de sua competência. Estabeleceu as responsabilidades e atribuições dos agentes que cooperam no processo.

Saeb e censo escolar somam-se, a partir daí, na viabilização do referido sistema de informações e indicadores educacionais.

A avaliação figurou também entre as diretrizes para os novos planos de carreira e remuneração do magistério dos estados, Distrito Federal e municípios, fixadas pela Resolução da Câmara de Educação Básica do Conselho Nacional de Educação de n.3, de 8.10.1997. Essa Resolução determinou que, entre outros, deverão constituir incentivos de progressão por qualificação do trabalho docente:

b) o desempenho no trabalho, mediante avaliação segundo parâmetros de qualidade do exercício profissional, a serem definidos em cada sistema;

e) [...] avaliações periódicas de aferição de conhecimentos na área curricular em que o professor exerça a docência e de conhecimentos pedagógicos. (Brasil, 1997, art. $6^{\circ}$, inc. VI)

Outro movimento de ampliação dos meios da avaliação/medida nacional da educação básica se deu com a Portaria n. 438, de 28.5. 1998 (Brasil, 
2002b), mediante a qual o Ministro da Educação instituiu o Exame Nacional do Ensino Médio "como procedimento de avaliação do desempenho do aluno", cujos objetivos seriam:

I- conferir ao cidadão parâmetro para auto-avaliação, com vistas à continuidade de sua formação e à sua inserção no mercado de trabalho;

II- criar referência nacional para os egressos de qualquer das modalidades do ensino médio;

III- fornecer subsídios às diferentes modalidades de acesso à educação superior;

IV- constituir-se em modalidade de acesso a cursos profissionalizantes pós-médios. (Brasil, 2002b, art. $1^{\circ}$ )

O exame, conforme essa Portaria, se propunha a avaliar

...competências e as habilidades desenvolvidas pelos examinandos ao longo do ensino fundamental e médio, imprescindíveis à vida acadêmica, ao mundo do trabalho e ao exercício da cidadania, tendo como base a matriz de competências especialmente definida para o exame $\left(\right.$ art. $\left.1^{\circ}\right)$

Castro ( 1 996) havia apontado tal medida e recomendado, inclusive, elevação progressiva de exigência de conhecimento para obtenção do diploma. Sem ter chegado a tanto, a norma propôs uma elevação de exigência a partir das alterações introduzidas pela Portaria Ministerial n. 3 I 8, de 22.2.200 I (Brasil, 2002a), por meio da qual foi dada uma nova redação ao art. $2^{\circ}$, alterando-se as competências a serem examinadas, acrescentando-se uma lista de 21 habilidades e cinco competências em redação.

Exemplificando: a Portaria n. 438/98 determina (em seu o art. $2^{\circ}$, § único, inc. I) que seja avaliada a seguinte competência: "demonstrar domínio básico da norma culta da Língua Portuguesa e do uso das diferentes linguagens: matemática, artística, científica, entre outras". A nova redação dada pela Portaria n. 3 | 8/ 200 I coloca tal determinação em novos termos: "Dominar a norma culta da Língua Portuguesa e fazer uso das linguagens matemática, artística e científica" (grifos nossos).

Os usos dos dados obtidos com o Enem deveriam observar o disposto no art. $6^{\circ}$ da Portaria n. 438/98, que menciona a estruturação de um banco de dados e emissão de relatórios pelo Inep disponíveis às Secretarias de Edu- 
cação e aos pesquisadores, resguardado o sigilo individual. Resultados individuais poderiam ser utilizados "mediante autorização expressa do candidato" ( $\S$ único, art. $7^{\circ}$ ). Acenando para usos diversos, o Inep, por meio da Portaria. n. 6/2000, anexo I, art. 3 I (Brasil, 2000a), dispôs que caberia ao participante autorizar a utilização de seus resultados a todos os segmentos sociais que the interessassem. No art. 32 previu o acesso a tais resultados pelos estabelecimentos de ensino pós-médio e superior e instituições do mercado de trabaIho, desde que obtivessem a autorização do examinado. Com a Portaria Inep n. 195/200 I, art. 24, § 1ª a autorização expressa foi substituída pelo fornecimento do número de inscrição no Enem pelo próprio examinado, facilitando usos dos resultados individuais (Brasil, 2002).

Para Sousa (1999, p.57), esse exame consiste em "medida de resultados" que "atribui apenas ao potencial do aluno o seu sucesso pessoal e profissional, abstraindo os fatores econômicos e sociais que lhe condicionam tal ou qual trajetória na escola e na vida", tendendo a prejudicar os alunos oriundos das escolas que têm precárias condições de funcionamento e que, tradicionalmente, atendem à população pobre. Essa perspectiva individualizada desconsidera as condições estruturais do Estado e do ensino brasileiros.

movimento que instituiu a avaliação nacional do rendimento escolar como domínio da ação da administração federal ocorreu também na esfera curricular a partir de dispositivos legais, mais especificamente do disposto no art. $9^{\circ}$, inc. IV da LDB/96.

Com a edição dos Parâmetros Curriculares Nacionais - PCNs - para o ensino fundamental (1995-1997), a administração federal apresentou aos professores e gestores educacionais, de todo o país, determinada concepção de avaliação, do ensino, da aprendizagem e da escola. No ensino fundamental, ela listou os conteúdos mínimos de aprendizagens essenciais quanto aos objetivos estabelecidos para cada "ciclo" e componente curricular, precisando as expectativas de aprendizagem e, por conseguinte, o que seria aferido mediante avaliação. No ensino médio, as expectativas de resultados a serem aferidos pela avaliação foram expressas em termos de competências e habilidades.

Mas, apreciando os PCNs do ensino fundamental, a Câmara de Educação Básica - CEB - do Conselho Nacional de Educação - CNE -, no Parecer de n. 3, aprovado em 12.3.1997, assim se pronunciava: 
Os PCN não dispensam a necessidade de formulação de diretrizes curriculares nacionais, que deverão fundamentar a fixação de conteúdos mínimos e a base nacional comum dos currículos, em caráter obrigatório para todo o território nacional, nos termos do artigo 26 da Lei 9.394/96 (LDB).

Tendo em vista os dispositivos constitucionais e legais pertinentes, a CEB exercitará a sua função deliberativa, formulando as Diretrizes Curriculares Nacionais - DCN. (Brasil, 200 Ig)

No cumprimento dessa função, em um contexto de tensão políticoinstitucional ${ }^{4}$, a CEB formulou diretrizes curriculares nacionais para a educação básica: ensino fundamental (Parecer n. 4 de 29.1. 1998 e Resolução n. 2 de 7.4.1998), ensino médio (Parecer n. 15 de 1.6.1998 e Resolução n. 3 de 26.6. 1998), educação infantil (Parecer n. 22 de 17.12.1998 e Resolução n. I de 7.4. 1999), educação de jovens e adultos (Parecer n. I I de 10.5.2000 e Resolução n. I de 5.7.2000), educação especial (Parecer n. 17 de 3.7.200| e Resolução n. 2 de | |.9.200|).

Como aparece nesses documentos normativos a avaliação da educação básica?

$\bigcirc$ parecer que aprova as diretrizes curriculares nacionais para o ensino fundamental, tendo como relatora Regina Alcântara de Assis, ao considerar os antecedentes de tais diretrizes, afirma:

...ao instituir e implementar um Sistema de Avaliação da Educação Básica, o MEC cria um instrumento importante na busca pela eqüidade, para o sistema escolar brasileiro, o que deverá assegurar a melhoria de condições para o trabalho de educar com êxito, nos sistemas escolarizados. A análise destes resultados deve permitir aos Conselhos e Secretarias de Educação a formulação e o aperfeiçoamento de orientações para a melhoria da qualidade do ensino.

A proposta de avaliação nacional deve propiciar uma correlação direta entre a Base Nacional Comum para a educação e a verificação externa do desempenho, pela qualidade do trabalho de alunos e professores, conforme regula a LDB, Art. $9^{\circ}$.

4 Bonamino, Martínez (2002) e Cury (2002) analisam a participação do MEC e do CNE no tocante ao currículo. 
Os esforços conjuntos e articulados de avaliação dos sistemas de educação, Federal, Estaduais, Municipais e do Distrito Federal propiciarão condições para o aperfeiçoamento e o êxito da Educação Fundamental. (Brasil, 200 lh)

Por sua vez, o parecer que aprova as diretrizes curriculares nacionais para o ensino médio, tendo como relatora Guiomar Namo de Mello, acentua a relação entre diretrizes curriculares e avaliação com vistas à eficiência e eqüidade. Destaca a avaliação como ferramenta para operar o controle, pela escola e pelos sistemas, da qualidade do projeto e do processo educacionais, e para propiciar a intervenção compensatória dessas instâncias, conforme mostram os trechos a seguir.

... a diversidade da escola média é necessária para contemplar as desigualdades nos pontos de partida de seu alunado, que requerem diferenças de tratamento como forma mais eficaz de garantir a todos um patamar comum nos pontos de chegada. Será indispensável portanto que existam mecanismos de avaliação dos resultados para aferir se os pontos de chegada estão sendo comuns. E para que tais mecanismos funcionem como sinalizadores eficazes, deverão ter como referência as competências de caráter geral que se quer constituir em todos os alunos e um corpo básico de conteúdos cujo ensino e aprendizagem, se bem-sucedidos, propiciam a constituição de tais competências. O Sistema de Avaliação da Educação Básica (Saeb) e, mais recentemente, o Exame Nacional do Ensino Médio (Enem), operados pelo MEC; os sistemas de avaliação já existentes em alguns estados e que tendem a ser criados nas demais unidades da federação; e os sistemas de estatísticas e indicadores educacionais, constituem importantes mecanismos para promover a eficiência e a igualdade.

A análise dos resultados das avaliações e dos indicadores de desempenho deverá permitir às escolas, com apoio das demais instâncias dos sistemas de ensino, avaliar seus processos, verificar suas debilidades e qualidades, e planejar a melhoria do processo educativo. Da mesma forma deverá permitir aos organismos responsáveis pela política educacional desenvolver mecanismos de compensação que superem gradativamente as desigualdades educacionais. (Brasil, 200।i )

A avaliação também foi considerada condição necessária da autonomia. Esta diretriz requer "qualificação permanente dos que trabalham na escola, em 
especial dos professores". Tal compromisso deve ser verificado, e a melhor forma para isso, segundo a relatora, seria: "... instituir mecanismos de prestação de contas que facilitem a responsabilização dos envolvidos”. Assim, tal diretriz trata de:

..."responsabilização", avaliação de processos e de resultados, participação dos interessados, divulgação de informações, que imprimam transparência às ações dos gestores, diretores, professores, para que a sociedade em geral e os alunos e suas famílias em particular, participem e acompanhem as decisões sobre objetivos, prioridades e uso dos recursos. (Brasil, 200 li)

Em vista disso, a relatora afirma que:

Mais uma vez, portanto, destaca-se a importância dos sistemas de avaliação de resultados e de indicadores educacionais que já estão sendo operados, ou os que venham a se instituir. Para a identidade e a diversidade, a informação é indispensável na garantia da igualdade de resultados. Para a autonomia ela é condição de transparência da gestão educacional e clareza da responsabilidade pelos resultados. (idem)

Alerta, a seguir, para requisitos indispensáveis à avaliação, a fim de que ela atinja seus propósitos.

Mas os sistemas de avaliação e indicadores educacionais só cumprirão satisfatoriamente essas duas funções complementares, se todas as informações por eles produzidas resultados de provas de rendimento, estatísticas e outras - forem públicas, no sentido de serem apropriadas pelos interessados, dos membros da comunidade escolar à opinião pública em geral. (idem).

A resolução referente a esse parecer estabeleceu que na observância da identidade, diversidade e autonomia as escolas e os sistemas de ensino:

III- instituirão sistemas de avaliação e/ou utilizarão os sistemas de avaliação operados pelo Ministério da Educação e do Desporto, a fim de acompanhar os resultados da diversificação, tendo como referência as competências básicas a serem alcançadas, a legislação do ensino, estas diretrizes e as propostas pedagógicas das escolas; 
IV- instituirão mecanismos e procedimentos de avaliação de processos e produtos, de divulgação dos resultados e de prestação de contas, visando desenvolver a cultura da responsabilidade pelos resultados e utilizando os resultados para orientar ações de compensação de desigualdades que possam resultar do exercício da autonomia (Brasil, $200 \mathrm{lj}$, art. $7^{\circ}$ )

exposto revela que, além da intensificação da dinâmica da regulação normativa concernente à avaliação da educação básica, viu-se ocorrer uma amplificação normativa. A avaliação permeou currículo, gestão escolar e desempenho docente, associando-os. Mostra-se aí uma faceta do regime federativo de colaboração.

No decorrer de 1997, o MEC conduziu o processo de elaboração do Plano Nacional de Educação - PNE -, com duração de dez anos, enviando ao Congresso Nacional projeto de lei que o instituía, por meio da Mensagem n. 180/98, de II.2.1998. Esse projeto foi antecedido por outro projeto de lei, apresentado à Câmara dos Deputados em 10.2.1998, concernente à proposta articulada pelo Fórum Nacional em Defesa da Escola Pública (com os trabaIhos do $1^{\circ}$ e $2^{\circ}$ Congresso Nacional de Educação - Coned) junto a diversos coletivos da sociedade civil.

A proposta do MEC iniciou sua tramitação na Câmara dos Deputados como Projeto de Lei n. 4.173/98, apensado ao segundo, Projeto de Lei n. 4. I55/98, em 13.3.1998. A tramitação desses projetos culminou na edição da Lei n. 10.172, de 9.1.200। (Brasil, 200। c).

Essa lei estabelece que, com base no plano aprovado, deverão ser, a partir de então, elaborados os planos decenais (e plurianuais) dos estados, Distrito Federal e municípios, sendo eles expressão de implementação do PNE. Implementação a ser avaliada periodicamente pela União, em articulação com essas esferas do Poder Público, e acompanhada em sua execução pelo Poder Legislativo. $\bigcirc$ art. $4^{\circ}$ da lei estabelece que: "A União instituirá o Sistema Nacional de Avaliação e estabelecerá os mecanismos necessários ao acompanhamento das metas constantes do Plano Nacional de Educação". $\bigcirc$ art. $6^{\circ}$ determina a tarefa conjunta na divulgação desse plano "para que a sociedade o conheça amplamente e acompanhe sua implementação".

A "melhoria da qualidade do ensino em todos os níveis" é um dos objetivos declarados no PNE. Para tanto, entre cinco prioridades estabelecidas, está o 
Desenvolvimento de sistemas de informação e de avaliação em todos os níveis e modalidades de ensino, inclusive educação profissional, contemplando também o aperfeiçoamento dos processos de coleta e difusão dos dados, como instrumentos indispensáveis para a gestão do sistema educacional e melhoria do ensino. (Brasil, 200 lc)

Como se vê, está prevista a ampliação da regulação central pela via da avaliação, conjugada com sistemas de informações que contem com quadro profissional especializado e aporte da informática. Também se prevê a absorção das funções de supervisão e inspeção nesse contexto, assim como a articulação de mecanismos de avaliação federais, estaduais e municipais. Há, nesse caso, fortes evidências a respeito do conteúdo/forma da reforma administrativa na educação. Conforme apontou Oliveira (2000), caminha-se para a substituição das estruturas burocráticas e hierárquicas por um modelo que segue a triIha das modificações que vêm ocorrendo na área da administração.

A reforma administrativa no campo da educação vai ganhando materialidade pela via da indução, do monitoramento, do controle e da avaliação. Tem-se explicitado assim, pela "mão" do Executivo federal, o papel regulador do Estado.

Voltando à esfera da norma jurídico-legal, há que se atentar para a relação entre a reforma administrativa da educação - que estabelece a regulação notadamente pela via da avaliação medida - e a reforma administrativa do setor público no Brasil.

Em 1998, a reforma administrativa - desenhada e, em boa medida, implementada a partir de ações do Executivo federal desde 1995 - configurouse no texto constitucional por meio da Emenda Constitucional n. 19, de 4.6. 1998 (Brasil, 2001 m). Com ela, o art. 39 da Constituição Federal fixou os princípios "de legalidade, impessoalidade, moralidade, publicidade e eficiência" da administração pública dos Poderes da União, dos Estados, do Distrito Federal e dos Municípios e, no inciso I do $\S 3^{\circ}$, reportou-se à exigência de assegurar a "avaliação periódica, externa e interna, da qualidade dos serviços" prestados pela administração pública, como dimensão das formas de participação dos usuários em tais serviços, a ser regulada em lei.

Esse fundamento jurídico-legal diz também respeito à administração pública da educação básica, já que a educação pública passou a ser considerada um dos "serviços" do Estado.

No término do segundo mandato de FHC, foi instituído o Exame Na- 
cional de Certificação de Competências de Jovens e Adultos - Encceja -, pela Portaria Ministerial n. 2.000, de 12.7.2002, cujo art. $2^{\circ}$ declarava o objetivo de "... avaliar competências e habilidades de jovens e adultos brasileiros, residentes no Brasil ou no exterior, que não tiveram acesso ou continuidade de estudos na idade própria, com aferição em nível de ensino fundamental e de ensino médio". Os objetivos específicos seriam:

I- oferecer referência individual para que jovens e adultos possam proceder à autoavaliação de competências e habilidades;

II- avaliar competências e habilidades, adquiridas pelos jovens e adultos, no processo escolar ou fora dele;

III- estruturar uma avaliação para jovens e adultos que sirva como referência às Instituições de Ensino credenciadas pelas Secretarias da Educação, para que procedam à expedição de históricos escolares, declarações de conclusão de série, e diplomas ou certificados de conclusão de curso, com as especificações cabíveis, conforme estabelece o inciso VII do artigo 24 da Lei 9.394/96;

IV- oferecer uma avaliação para fins de classificação na correção do fluxo escolar; V- estruturar uma avaliação para jovens e adultos habilitando-os ao prosseguimento de estudos em caráter regular;

VI- consolidar e divulgar um banco de dados com informações técnico-pedagógicas, metodológicas, operacionais, socioeconômicas e culturais que possa ser utilizado para a melhoria da qualidade na oferta de educação de jovens e adultos e dos procedimentos relativos ao Encceja. (Brasil, 2002c, art. $3^{\circ}$ )

Esses objetivos ambiciosos não só evidenciam a crença depositada em tal mecanismo de regulação como, sobretudo, a dimensão do compromisso estatal com essa população.

Além da edição de normas e da implementação de programas, foram realizados alguns eventos nos quais se discutiu a organização do sistema nacional de informação abarcando o sistema nacional de avaliação (Wolynec, 1999). A análise dos anais desses eventos mostrou ter sido privilegiada a interlocução com agentes e especialistas externos.

O quadro I oferece uma visão esquemática do conjunto das normas editadas, dos programas implementados e dos eventos realizados no período. 
QUADRO I

AVALIAÇÃO E MEDIDA DA EDUCAÇÃO BÁSICA NO BRASIL, DE 1995 A 2002

\begin{tabular}{|c|c|c|c|}
\hline \multirow{2}{*}{ ANO } & \multicolumn{3}{|c|}{ CATEGORIAS } \\
\hline & NORMAS & AÇÕES & EVENTOS \\
\hline 1995 & $\begin{array}{l}\text { MP } 967 \text { de } 13 / 4 / 95 \\
\text { MP } 992 \text { de } 12 / 5 / 95 \\
\text { MP } 1.094 \text { de 28/8/95 } \\
\text { Lei n. } 9.13 \text { I de 24/I I/95 } \\
\text { PCNs Ensino Fundamental }\end{array}$ & $\begin{array}{l}\text { Avaliação do livro didático } \\
3^{\circ} \text { Ciclo Saeb }\end{array}$ & $\begin{array}{l}\text { Seminário Internacional de } \\
\text { Avaliação Educacional - 16, } \\
\text { I7 e 18/10/95 }\end{array}$ \\
\hline 1996 & $\begin{array}{l}\text { Emenda Constitucional n. } 14 \\
\text { de } 12 / 9 / 96 \\
\text { Lei n. 9.394, de 20/12/96 } \\
\text { Lei n. 9.424, de 24/12/96 } \\
\text { - Fundef/Censo Escolar } \\
\text { PCNs Ensino Fundamental }\end{array}$ & Avaliação do livro didático & \\
\hline 1997 & $\begin{array}{l}\text { Decreto n. 2.264/97 } \\
\text { Fundef/Censo Escolar } \\
\text { Res. CNE n. } 3 \text { de 8/I0/97 } \\
\text { - Avaliação no Plano de } \\
\text { Carreira do Magistério }\end{array}$ & $\begin{array}{l}\text { Avaliação do livro didático } \\
4^{\circ} \text { Ciclo Saeb }\end{array}$ & $\begin{array}{l}\text { Seminário Internacional sobre } \\
\text { Avaliação do EM e Acesso ao } \\
\text { ES 30/6 a 2/7/97 } \\
\text { Seminário Internacional de } \\
\text { Avaliação Educacional - dez. } \\
1997\end{array}$ \\
\hline 1998 & $\begin{array}{l}\text { Emenda Constitucional n. } 19 \text {, } \\
\text { de 4/6/1988 } \\
\text { Portaria Ministerial n. 177/98 } \\
\text { - Censo Escolar } \\
\text { Portaria n. 438, de 28/5/ } \\
\text { 1988 - institui Enem } \\
\text { Res. CNE n. I, de 7/4/99 - } \\
\text { Diretrizes Curriculares da El } \\
\text { Res. CNE n. 2, de 7/4/98 - } \\
\text { Diretrizes Curriculares do EF } \\
\text { Res. CNE n. 3, de 26/6/98 - } \\
\text { Diretrizes Curriculares do EM }\end{array}$ & $\begin{array}{l}\text { Avaliação do livro didático } \\
\text { Enem }\end{array}$ & $\begin{array}{l}\text { Primeiro diálogo Brasil-EUA: } \\
\text { Avaliação e Indicadores da } \\
\text { Educação Básica. RJ, fev. } 1998\end{array}$ \\
\hline 1999 & & $\begin{array}{l}\text { Avaliação do livro didático } \\
5^{\circ} \text { Ciclo Saeb } \\
\text { Enem }\end{array}$ & \\
\hline
\end{tabular}

(continua) 
(continuação)

\begin{tabular}{|c|c|c|c|}
\hline \multirow{2}{*}{ ANO } & \multicolumn{3}{|c|}{ CATEGORIAS } \\
\hline & NORMAS & AÇÕES & EVENTOS \\
\hline 2000 & $\begin{array}{l}\text { Portaria n. 82/2000- } \\
\text { Avaliação do livro didático } \\
\text { Res. CNE n. I, de 5/7/2000 - } \\
\text { Diretrizes Curriculares da EJA } \\
\text { Enem }\end{array}$ & & \\
\hline 2001 & $\begin{array}{l}\text { Lei n. } 10.172 \text { - PNE: Institui- } \\
\text { ção do Sistema Nacional de } \\
\text { Avaliação/Diretrizes e metas } \\
\text { para dez anos } \\
\text { Portaria n. } 318 \text {, de 22/2/200 I } \\
\text { - altera Enem }\end{array}$ & $\begin{array}{l}6^{\circ} \text { Ciclo Saeb } \\
\text { Enem }\end{array}$ & \\
\hline 2002 & $\begin{array}{l}\text { Portaria n. 2.270, de 14/ } \\
8 / 2002 \text {-institui o Encceja } \\
\text { Portaria Inep n. } 77 \text { de } 16 / \\
8 / 2002 \text { - regulamenta } \\
\text { Encceja em } 2002\end{array}$ & Enem & \\
\hline
\end{tabular}

\section{CONSIDERAÇÕES FINAIS}

Do exposto, importa destacar alguns pontos relevantes para o objetivo anunciado neste trabalho, sem que se dê por esgotada a análise e a interpretação dos dados.

O primeiro deles diz respeito à extensão da regulação normativa federal concernente à avaliação da educação básica, no período de 1995 a 2002. Conforme visto, foram ampliados extraordinariamente os meios e o instrumental de regulação federal da "qualidade" do ensino, conjugando-se as vias de medida e avaliação. A intervenção normativa do Executivo federal foi intensa, indicando sempre as alterações constitucionais e a edição de leis, ampliando a regulamentação da área e amplificando a regulação normativa federal.

Nesse período, acentuou-se, por um lado, a subordinação do órgão deliberativo, normativo e fiscalizador nacional (CNE) ao MEC, que com sua ação normativa, reforçou a regulação federal pela via da avaliação. Por outro 
lado, o Inep concentrou poder decisório e operacional, tornando-se o órgão avaliador e mensurador da educação no país.

A dinâmica da regulação normativa do período evidenciou uma faceta do regime federativo de colaboração. No caso específico da avaliação, concretizou a centralização, conforme Oliveira (2000). Como evidência da concentração do poder de decisão encontra-se um leque de recursos normativos que, como regulação formal, adentrou o currículo, interferiu na organização escolar, redefiniu a gestão educacional, fixou a qualidade a ser obtida e seus parâmetros. Sobretudo, restringiu a emergência da avaliação pelos caminhos da gestão democrática.

Apenas no caso da avaliação do desempenho do docente da educação básica, a regulação normativa não avançou. Em entrevista ao Jornal do MEC, Juan Enrique Froemal, diretor-técnico do Laboratório Latino-Americano de Avaliação da Qualidade da Educação, instituição da Unesco responsável por desenvolver pesquisas de medição da qualidade do ensino na região, destacou a dificuldade política dessa avaliação e considerou plausível a alternativa de privilegiar a avaliação da formação desse profissional, o que tem ocorrido particularmente no processo de avaliação da educação superior brasileira (Brasil, 2002d).

Acentuou-se a importância da avaliação da educação básica de tal modo que, de estratégia, passou a ser política, conforme destacou Maria Helena Guimarães de Castro (1998), presidente do Inep. Passou também a compor o Sistema Integrado de Informações Educacionais - SIEd -, juntamente com outras iniciativas de avaliação e de informação. Mas chegou a 2002 defrontando-se com problemas e desafios de ordem metodológica, política e pedagógica.

Até meados dos anos de 1980, conforme ressalta Gomes (2002), o Brasil não tinha avaliação no âmbito dos sistemas ou redes escolares e tinha problemas comuns aos países que não a possuíam. Chegou porém ao século XXI partilhando dos problemas desse grupo, cada vez mais numerosos, mas fazendo parte dos países que têm avaliação de sistema. Surge assim o paradoxo: o de um país com tradição de graves problemas avaliativos no processo de ensinoaprendizagem ingressar no processo de avaliação da educação no nível macro.

Mas, a realidade educacional não se deixa conhecer por inteiro, mesmo que se disponha de um aparato regulador em contínua calibração. Ela insiste em descortinar os estreitos limites dentro dos quais tal aparato ope- 
ra, bem como as análises reducionistas que propicia, conforme alertou Santos (2002).

Das considerações desta autora infere-se que a qualidade da educação básica está menos referida à existência e correspondência a padrões externamente estabelecidos e centralmente controlados do que à escassez de políticas públicas conjugadas e efetivas sobre o atendimento de necessidades de grande parte da população brasileira. Essa falta determina a escola real, cuja eficácia é cotidianamente problematizada pelo compartilhar do "mal-estar social" comum a alunos e docentes.

O segundo ponto a considerar é que não se pode atribuir ao Governo FHC (I 995 a 2002) exclusiva responsabilidade pelo modelo de avaliação nacional da educação básica e sua lógica, pois ele vicejava antes mesmo da formulação de sua proposta para o governo. Talvez se deva pensar que esse governo teve sua intervenção (na esfera da avaliação/medida) alargada no tempo, com a continuação de iniciativas preexistentes e com a exploração de uma tendência evidenciada no próprio processo de emergência da "avaliação nacional" na agenda estatal brasileira.

terceiro ponto a destacar diz respeito ao viés privatista da avaliação da educação básica. Desde a origem do Saeb, podem-se ver canais abertos à visão e à experiência do setor privado, em um movimento que seguiu rumo à terceirização de parte das atividades do Saeb e do Enem, ao tempo em que se reduzia a audição e o envolvimento do setor público, dos diretamente interessados e da sociedade organizada. Cabe inquirir se a competência científicotécnica do setor privado consegue suplantar sua escassa familiaridade com a escola pública real, produto de um país plural e profundamente iníquo ou se a avaliação, porque sofisticada do ponto de vista técnico e científico, pode prescindir do saber que verte de tal familiaridade, assim como da dimensão política da avaliação.

quarto ponto a merecer atenção refere-se ao locus privilegiado de discussão da avaliação da educação básica. Até 1994, a discussão da avaliação nacional da educação básica foi feita basicamente em círculos nacionais, tendo sido realizado um Seminário Nacional sobre Medidas Educacionais em 1992, com significativa participação de docentes e pesquisadores de universidades públicas brasileiras.

Mas, a partir de 1995 passou-se a privilegiar a audição e interação com especialistas internacionais, de que são exemplos: o Seminário Internacional de 
Avaliação da Educação, realizado de 16 a 18 de outubro de 1995 no Rio de Janeiro; o Seminário Internacional de Avaliação Educacional, realizado de $1{ }^{\circ}$ a 3 de dezembro de 1997 no Rio de Janeiro; o Seminário Internacional sobre Avaliação do Ensino Médio e Acesso ao Ensino Superior, realizado de 30 de junho a 2 de julho de 1997 em Brasília. Esse deslocamento acentuou-se com a centralização da avaliação educacional no Inep, viabilizada em 1997, com a reestruturação para transformá-lo em autarquia.

Embora não se ignore algum grau de interlocução do Inep com "especialistas" e administradores de experiências de avaliação em instâncias subnacionais, bem como as esporádicas participações de autoridades daquele órgão em espaços de discussão da educação básica, pode-se afirmar que prevaleceu a ausência do debate nacional. A própria sofisticação técnica da avaliação nacional - que hoje ocupa a atenção da cúpula decisória e de seus assessores - apresenta-se como entrave para a compreensão, tanto pelos atores dos sistemas e escolas como pela população em geral, do processo avaliativo realizado.

O quinto ponto a destacar diz respeito ao contexto mais amplo de "leitura" de medidas governamentais, como a da avaliação nacional da educação básica. Nessa direção, pode-se afirmar que as iniciativas federais do período de 1995 a 2002 indicam uma das vias pelas quais vem ganhando forma objetiva, no Brasil, o Estado regulador e avaliador (Afonso, 1998) em lugar do Estado-Executor. Isso, aliás, foi declarado pela própria presidente do Inep em palestra inaugural do Seminário Internacional de Avaliação de 1997, quando afiançou:

...com a atual reforma, sai de cena o Estado-executor, assumindo seu lugar o Estado-regulador e o Estado-avaliador. Essa mudança de paradigma exige uma verdadeira reengenharia do setor público. Trata-se da difícil tarefa de substituir controles burocráticos por uma nova cultura gerencial, que incorpora a política de avaliação como elemento estratégico da gestão pública. (Castro, 1998, p.9)

Por fim, cabe destacar que, na perspectiva de efetivação, ainda está para ser comprovada a eficácia de tão extensa e intensa ação normativa governamental, bem como da regulação federal da educação básica pela via da avaliação/medida. $\bigcirc$ mesmo se pode dizer quanto à efetividade desta na relação "regulação e boa-governança". Pois, em que pesem os discursos e as estatísticas sobre avanços obtidos, a rigor pouco se pode atribuir à avaliação em ter- 
mos de ganhos quanto ao exercício dinâmico do ato de governar, da capacidade de governo do próprio Estado na área da educação, em termos de credibilidade e capacidade política.

Todavia, não resta dúvida de que a produção normativa constituiu um nível de intervenção na realidade, sendo, antes de tudo, expressão de como se exerce o poder e de como tem ocorrido a concreção do Estado-Regulador no Brasil.

\section{REFERÊNCIAS BIBLIOGRÁFICAS}

AFONSO, A. J. Politicas educativas e avaliação educacional: para uma análise sociológica da reforma educativa em Portugal ( 1985 - 1995). Braga: Universidade do Minho, 1998.

BARRETTO, E. S. de S. et al. Avaliação na educação básica (I 990 - 1998). Brasília: MEC/ Inep, 200I. (Série Estado do Conhecimento, 4)

BONAMINO, A.; MARTíNEZ, S. A. Diretrizes e Parâmetros Curriculares Nacionais para o ensino fundamental: a participação das instâncias políticas do Estado. Educação \& Sociedade, v.23, n.80, p.37I-388, set. 2002

BRASIL. Lei n. 4.024, de 20 de dezembro de 1961. Estabelece as diretrizes e bases da educação nacional. In: BRASIL. Congresso. Senado. 500 anos de legislação brasileira. 2. ed. Brasília, 2001. CD3: Brasil República.

Lei n. 9.131, de 24 de novembro de 1995. Altera dispositivos da Lei n. 4.024, de 20 de dezembro de 196I, e dá outras providências: In: BRASIL. Congresso. Senado. 500 anos de legislação brasileira. 2. ed. Brasília, 200 I a. CD3: Brasil República.

Lei n. 9.394, de 20 de dezembro de 1996. Estabelece as diretrizes e bases da educação nacional. Diário Oficial da República Federativa do Brasil, 23 dez. 1996. Disponível em: <http.www.mec.gov.br>. Acesso em: 4 abr. 1999.

Lei n. 9.424, de 24 de dezembro de 1996. Dispõe sobre o Fundo de Manutenção e Desenvolvimento do Ensino Fundamental e de Valorização do Magistério, na forma prevista no art. 60, § $7^{\circ}$. Do Ato das Disposições Constitucionais Transitórias e da outras providências. In: BRASIL. Congresso. Senado. 500 anos de legislação brasileira. 2. ed. Brasília, 200 Ib. CD3: Brasil República.

Lei n. 10.172, de 9 de janeiro de 200 I. Aprova o Plano Nacional de Educação e dá outras providências. In: BRASIL. Congresso. Senado. 500 anos de legislação brasileira. 2. ed. Brasília, 200 Ic. CD3: Brasil República. 
Medida Provisória n. 66I, de 1994. In: BRASIL. Congresso. Senado. 500 anos de legislação brasileira. 2. ed. Brasília, 200 Id. CD3: Brasil República.

Medida Provisória n. 765, de 1994. In: BRASIL. Congresso. Senado. 500 anos de legislação brasileira. 2. ed. Brasília, 200 I e. CD3: Brasil República.

Medida Provisória n. 967, de 1994. In: BRASIL. Congresso. Senado. 500 anos de legislação brasileira. 2. ed. Brasília, 200 If. CD3: Brasil República.

BRASIL. Conselho Nacional de Educação. Parecer CNE/CEB n. 3, de 12 de março de 1997. Brasília, 1997. Disponível em: <http://www.mec.gov.br>. Acesso em: mar. $200 \mathrm{lg}$.

Parecer CNE/CEB n. 4, de 29 de janeiro de 1998. Diretrizes Curriculares Nacionais para o Ensino Fundamental. Brasília, 1997. Disponível em: <http:// www.mec.gov.br>. Acesso em: mar. $200 \mathrm{lh}$.

Parecer CNE/CEB n. 15, de ${ }^{\circ}$ de junho de 1998. Diretrizes Curriculares Nacionais para o Ensino Médio. Conselho Nacional de Educação, Brasília, 1997. Disponível em: <http://www.mec.gov.br>. Acesso em: mar. 200 li.

Resolução CEB/CNE n. 3, de 8 de outubro de 1997. Fixa diretrizes para os novos planos de carreira e remuneração para o Magistério dos estados, do Distrito Federal e dos municípios. Diário Oficial da República Federativa do Brasil. Brasília, seção I, p. 22.987, 13 out. 1997.

Resolução CNE/CEB n. 3, de 26 de junho de 1998. Brasília, 1997. Institui as Diretrizes Curriculares Nacionais para o Ensino Médio. Disponível em: <http:// www.mec.gov.br>. Acesso em: mar. $200 \mathrm{lj}$.

BRASIL. Constituição (1988). Constituição da República Federativa do Brasil. Brasília: Senado, 1988.

Decreto n. 2.264, de 27 de junho de 1997. Regulamenta a Lei n. 9.424, de 24 de dezembro de 1996 no âmbito federal, e determina outras providências. In: BRASIL. Congresso. Senado. 500 anos de legislação brasileira. 2. ed. Brasília, 200 lk. CD3: Brasil República.

Emenda Constitucional n. 14, de 12 de setembro de 1996. In: BRASIL. Congresso. Senado. 500 anos de legislação brasileira. 2. ed. Brasília, 200 H. CD3: Brasil República.

Emenda Constitucional n. 19, de 4 de junho de 1998. In: Brasil. Congresso. Senado. 500 anos de legislação brasileira. 2. ed. Brasília, 2001 m. CD3: Brasil República. 
BRASIL. Ministério da Educação. Portaria n. 6, de 25 de janeiro de 2000. Estabelece sistemática e disposições para a realização do Enem no ano 2000. Diário Oficial da União, Seção I, 28 jan. 2000.

Portaria n. 82, de 20 de janeiro de 2000. Estabelece a avaliação do livro didático como parte do Plano Nacional do Livro Didático. Ministério da Educação. Diário Oficial da União, seção I, 21 jan. 2000a.

Portaria n. 195, de 28 de dezembro de 200l (com alterações introduzidas pela Portaria Inep n. 7, de 29 de janeiro de 2002). Estabelece sistemática e disposições para a realização do Enem no ano 2002. Instituto Nacional de Estudos e Pesquisas Educacionais. Diário Oficial da União, 23 fev. 200 I. Disponível em: < http:/ /www.inep.gov.br>. Acesso em: 20 out. 2002.

Portaria n. 318, de 22 de fevereiro de 2001. Altera a Portaria n. 438, de 28 de maio de 1998. Disponível em: <http://www.inep.gov.br>. Acesso em: 20 out. $2002 a$.

Portaria n. 438, de 28 de maio de 1998. Institui o Exame Nacional do Ensino Médio. Disponível em: <http://www.inep.gov.br>. Acesso em: 20 out. 2002b.

Portaria n. 1.795, de 27 de dezembro de 1994. Cria o Sistema Nacional de Avaliação da Educação Básica. Diário Oficial da União, Brasília, seção I , n. 246, p.20.767-20.768, 28 dez. 1994.

Portaria n.2.000, de 12 de julho de 2002. Institui o Exame Nacional de Certificação de Competências de Jovens e Adultos. Diário Oficial da União, seção I, I 5 jul. 2002c.

p.8-9, abr. 2002d.

Professores devem ou não ser avaliados? Entrevista. Jornal do MEC, n. 17 ,

CASTRO, C. de M. Avaliação e reforma do ensino médio. In: SEMINÁRIO INTERNACIONAL DE AVALIAÇÃO DA EDUCAÇÃO. Rio de Janeiro, 16 a 18 de out. 1995. Anais. Brasília: MEC, 1996. p.I31-150. (Conferência)

CASTRO, M. H. G. de. Palestra inaugural. In: SEMINÁRIO INTERNACIONAL DE AVALIAÇÃO EDUCACIONAL. Rio de Janeiro, 1997. Anais. Brasília: MEC, 1998.

CEPAL. Formulacion y evaluacion de proyectos sociales. Chile: Proposal, 1995.

COSTA, S. L. da. (Des)governo, (in)governabilidade ou (des)governança? Revista de Administração Pública, Rio de Janeiro, v.31, n. I, p.42-74, mar./abr. 1997.

CUNHA, L. A. Educação brasileira: projetos em disputa. São Paulo: Cortez, 1995. 
CURY, R. J. A Educação básica no Brasil. Educação \& Sociedade, Campinas, v.23, n.80 esp., p. 169-200, set. 2002.

FERRER, A. T. Avaliação e mudança de sistemas educacionais: a interação que falta. In: SEMINÁRIO INTERNACIONAL DE AVALIAÇÃO DA EDUCAÇÃO. Rio de Janeiro, 1995. Anais. Brasília: MEC, 1996. p.33-54.

FRANCO, C. O Saeb - Sistema de Avaliação da Educação Básica: potencialidades, problemas e desafios. Revista Brasileira de Educação, n. I7, p. I27-I.333, maio/ago. 200 I.

FREITAS, L. C. de. (org.). Avaliação: construindo o campo e a crítica. Florianópolis: Insular, 2002.

GOMES, C. A. da C. Tendências nacionais da avaliação em educação: problemas de um país que passou a ter avaliação. Gestão em Ação, Salvador, UFBA, v.5, n. I , p.9- 16, jan./ jun. 2002.

LOCATELLI, I. Construção de instrumentos para a avaliação de larga escala e indicadores de rendimento: o modelo Saeb. Estudos em Avaliação Educacional, n.25, p.3-2I, jan./dez. 2002.

OLIVEIRA, R. P. de. Reformas educativas no Brasil na década de 90. In: CATANI, A. M.; OLIVEIRA, R. P. (orgs.) Reformas educacionais em Portugal e no Brasil. Belo Horizonte: Autêntica, 2000.

SANTOS, L. L. de C. P. Políticas públicas para o ensino fundamental: Parâmetros Curriculares Nacionais e Sistema Nacional de Avaliação (Saeb). Educação \& Sociedade, v.23, n.80, p.349-370, 2002.

SOUSA, S. Z. L. Avaliação do rendimento escolar como instrumento de gestão educacional. In: OLIVEIRA, D. A. (org.) Gestão democrática da educação: desafios contemporâneos. Petrópolis: Vozes, 1997. p.264-283.

A que veio o Enem? Revista de Educação AEC, Brasília, v.28, n. I I3, p.5360, out./dez. 1999.

WOLYNEC, E. Produção de estatísticas e indicadores educacionais. comparabilidade internacional e incorporação de novos indicadores. 1999. mimeo.

Recebido em: maio 2003

Aprovado para publicação em: julho 2004 